\title{
A FRAMEWORK FOR SUBCONTRACTOR SELECTION IN THE CONSTRUCTION INDUSTRY
}

\author{
Hamidreza Abbasianjahromi ${ }^{1}$, Hossein Rajaie ${ }^{2}$, Eqbal Shakeri ${ }^{3}$ \\ Department of Construction Engineering and Management, Amirkabir University of Technology, \\ Hafez Ave, 15914 Tehran, Iran \\ E-mails: ${ }^{1}$ abasian.hamid@gmail.com; ${ }^{2}$ rajaieh@aut.ac.ir (corresponding author); ${ }^{3}$ eshakeri@aut.ac.ir \\ Received 07 Apr. 2011; accepted 07 Jul. 2011
}

\begin{abstract}
The present condition of the construction industry imposes onerous responsibilities on contractors so they are very eager to subcontract some of their works. Subcontractors who directly handle a major portion of all construction activities have a highlighted role in the building industry, so suitable subcontractor selection has a direct effect on the productivity of construction operations. This paper aims to develop a comprehensive model for subcontractor selection based on the fuzzy preference selection index. The improvement of the proposed model lies in the fact that it has found a way to eliminate the weighting criteria phase in selecting the optimal subcontractor where weighting attributes is a challenging task. The consistency test is presented for investigating the accuracy of model results with the previous scientific work.
\end{abstract}

Keywords: subcontractor selection, fuzzy preference selection index, multi-criteria decision making, fuzzy set theory.

Reference to this paper should be made as follows: Abbasianjahromi, H.; Rajaie, H.; Shakeri, E. 2013. A framework for subcontractor selection in the construction industry, Journal of Civil Engineering and Management 19(2): $158-168$.

\section{Introduction}

New contracts (e.g. EPC, BOT, MC) have imposed various and onerous responsibilities on contractors, so they are very eager to subcontract some of their works. Many general contractors (GCs) only act as construction management agents in construction projects and sub-contract a large volume of their work to subcontractors (SCs) (Shash 1998). Subcontractors were born not only for enduring some of GC's responsibilities but also for doing some professional activities such as concrete tasks, welding tasks, etc. (Shimizu, Cordoso 2002). It can be concluded that the selection of appropriate SCs has a direct influence on many branches in the organization and project management area. Firstly, most of SC activities deal with construction tasks so they directly influence on the quality of projects. Selection of highly qualified SCs promotes the overall quality of projects and as a result, quality management can be implemented in the project. Secondly, because GCs will be evaluated in the next qualifications for future works, the good performance of SCs can be affected on the rate of GC's qualification. Thirdly, regarding the management role of GCs, control and monitoring of SC activities are one of the most important duties. Selection of strong SCs facilitates this process. The other field is cost area.
Implementing proper cost management by GC and SCs would result in considerable money saving for each project. Finally, regarding the time point of view, it is very important that the execution team be able to finish project tasks on a planned schedule. Owning that SCs do special and critical tasks in many projects, time management has been merged to the SC management.

According to the highlighted role of SCs in construction, an appropriate selection of SCs is one of the most critical tasks. In another point of view, proper selection of SCs shows a different view when the peculiarity of the construction industry leads to no two projects being the same in various terms of project targets, management system, design, complexity, execution, personnel, site condition, etc. Owning to the importance of SC selection, researchers developed various investigations in this area (Arslan et al. 2008; Elazouni, Metwally 2000; Hartmann et al. 2009; Mbachu 2008; Shash 1998; Shimizu, Cordoso 2002; Tserng, Lin 2002; Yin et al. 2009) but they are not adequate and most researches conducted in this field have been limited to GC selection (Ahmad, Minkara 1988; Diekmann 1981; Fong, Choi 2000; Hatush, Skitmore 1998; Shash 1993; Sing, Tiong 2005; Oo et al. 2008; Zavadskas et al. 2010). GC selection has a basic difference with SC selection because, in 
practice, most GCs tend to subcontract work to someone who has a good context with their companies while in GC selection this item is not considered very much. Although in this process GC is placed as an owner, implementing the model used for GC selection is not suitable for SC selection. Developing a practical and simple model for SC evaluation in the selection phase is one of the best ways in promoting assurance for completing a project with expected targets. Therefore, developing a model for SC selection is the most important aim of this paper. The lack of documented information in most contractor companies causes the authors to offer a conceptual model based on expert judgments. In general, this type of model would not only match the condition with inadequate information but can also facilitate the process of evaluation. Maniya and Bhatt (2010) stated that the preference selection index (PSI) method is a novel tool to select the best alternative from given alternatives without deciding on the relative importance between attributes. The fuzzy preference selection index (FPSI) approach is offered by this paper for easy application, with regard to the uncertain nature of the construction industry, lack of strong documentation system in most contractor companies and satisfying a user-friendly model in SC selection. The remainder of this paper is organized as follows; initially, a review of the literature is provided. After this section, the proposed model will be presented and for illustrating the application of the suggested method, an example will be brought forth in a hypothetical manner. In the next section, a consistency test is offered for comprising results with previous models. Finally, in the conclusion section, a brief review will be conducted on the paper's results.

\section{Literature review}

Regarding the application of two concepts including SC selection and multi-criteria decision-making, these two contexts are separately taken into account in the following section:

a) SC selection. Contractor selection was used by many researchers as a subject for investigation but SC selection is a recent subject, especially in the construction industry. Ahmad and Minkarah (1988), Shash and Abdul-Hadi (1993) addressed the competitive system qualitatively. Their studies attempted to determine the factors affecting a contractor's bidding strategy. They investigated each factor's level of importance according to the contractor's decision to bid and the size of the markup. The other point of view was the work conducted by Elazouni and Metwally (2000). They suggested a framework based on a decision support system in subcontracting the best portion of the work. In their system, financial terms and scheduling plan are the most important criteria for planning the assignment of subcontractors. Tserng and Lin (2002) opined that subcontracting a supply chain of construction projects is considered as a global procurement system and an optimal combination of SCs can be obtained with this system. They proposed a web-based decision support system for trading-off between risk and profit in SC selection. Arslan et al. (2008) spoke of a webbased SC evaluation system called WEBSES by which the SCs can be evaluated based on combined criterion. Their model prepares useful tools for minimizing time and cost consumed in SC selection. This model basically works based on a strong database. Updating database in each situation, especially when there is lack of historical records, leads their model not be applicable properly. Mbachu (2008) surveyed contractors and SCs in South Africa and also applied multiattribute techniques for analyzing data. He showed that the quality record is the most influential criterion for prequalification of SCs and the tender price is the most significant influence in the subcontractor award. Finally, based on his findings, he suggested a framework for evaluation of SCs. Xiaolin et al. (2008) proposed a model based on benchmarking thinking. They established a virtual benchmark partner having whole optimization selection indexes and then applied case-based reasoning to measure the similarity degree. As a result, the descending list of partners can finally be obtained. Even though they declared their model as the initial format of their later research, the amount of calculation and mathematical theory in their model is very high and complicated, therefore their model is not applicable for all GCs with various levels. The importance of four factors including price, technical know-how, quality, and cooperation in the selection process was investigated in Singapore by Hartmann et al. (2009). According to their investigation, price criterion is the most important attribute, which GCs do not intend to discount, but they will accept the low performance of a known subcontractor on the remaining criteria. Yin et al. (2009) applied a data envelopment analysis for the evaluation of SC indexes in the selection phase. Their framework consists of two steps including primary selection and excellent SC selection. If each SC can pass two phases, it can be qualified for contracting.

Studying the previous work reveals that three main categories exist in SC selection. The first group is researches conducted in the evaluation of factors influenced on SC selection in different countries and the second group is an investigation developed a framework or model for SC selection. Finally, there were researchers who developed models for subcontracting the best portion of the work. Considering that this paper aims to develop a framework in SC selection, the literature review shows that the application of a step-by-step framework in SC selection is developing and use of organized frameworks for SC selection is slowly moving away from the traditional approaches towards a combination of qualitative and 
quantitative approaches. In this way, applying criteria for measuring SCs is inevitable. Based on this point of view, proposing a framework, which can formulate decision-making is the greatest concern of researchers.

b) Application of MCDM approaches in the construction industry. Multiple-criteria decision making (MCDM) is the most applicable tool in the selection and evaluation process especially in the construction industry. Many investigations have been conducted in these areas in various fields such as project selection (Ravanshadnia et al. 2010a, 2011; Wang et al. 2009a), contractor selection (Fong, Choi 2000; Mahdi et al. 2002), partner selection (Ravanshadnia et al. 2010b), risk assessment (Wang, Elhag 2006; Zeng et al. 2007), supplier selection (Ghoudsypour, O'Brien 1998; Wang et al. 2009b), plant location selection (Chu 2002), material selection (Jee, Kang 2000; Edwards, Deng 2007), etc. Combining MCDM approaches with the fuzzy theory is a new viewpoint which can properly deal with dark and vague conditions of the construction industry in the decision making phase. Especially in companies with no strong historical records, most judgment and decision making is made by experts. There are several researches combined with MCDM approaches and the fuzzy set theory (Fodor, Roubens 1994; Gheorghe 2005; Kahraman et al. 2007; Mikhailov 2004; Zhang 2004).

In the most developed models based on fuzzy MCDM, weighting criteria is a crucial phase. Attributed weights are not concrete in all situations; therefore, a limitation exists regarding their use. Considering this constraint, this paper aims at developing a model for selecting the best SC without directly deciding on the relative importance between attributes.

\section{The proposed framework for subcontractor selection}

Feedbacks obtained from the literature review clearly show that developing a step by step MCDM model for selection of SCs is preferable. The proposed model should be simple and also applicable in various conditions. A schematic of the SC selection model suggested in this paper is shown in Fig. 1. The model is broken down into two main steps: identification of SCs and ranking and selection. In some circumstances weighting attributes are challenging and time-consuming tasks, for example:

1. Where there is lack of time for decisionmaking;

2. Where there are some conflict opinions about the importance of criteria;

3. Where there is incompletely known information or uncertain data about the attributes.

In these situations or similar circumstances, the preference selection index (PSI) method is more practical. In this method, it is not necessary to assign relative importance among criteria, but overall preference value of each criterion is calculated using the concept of statistics. For user consolation, the fuzzy set theory is applied for working with linguistic terms. In other words, because of uncertainty, inability to well-defined the boundaries of set of observations and imprecise data

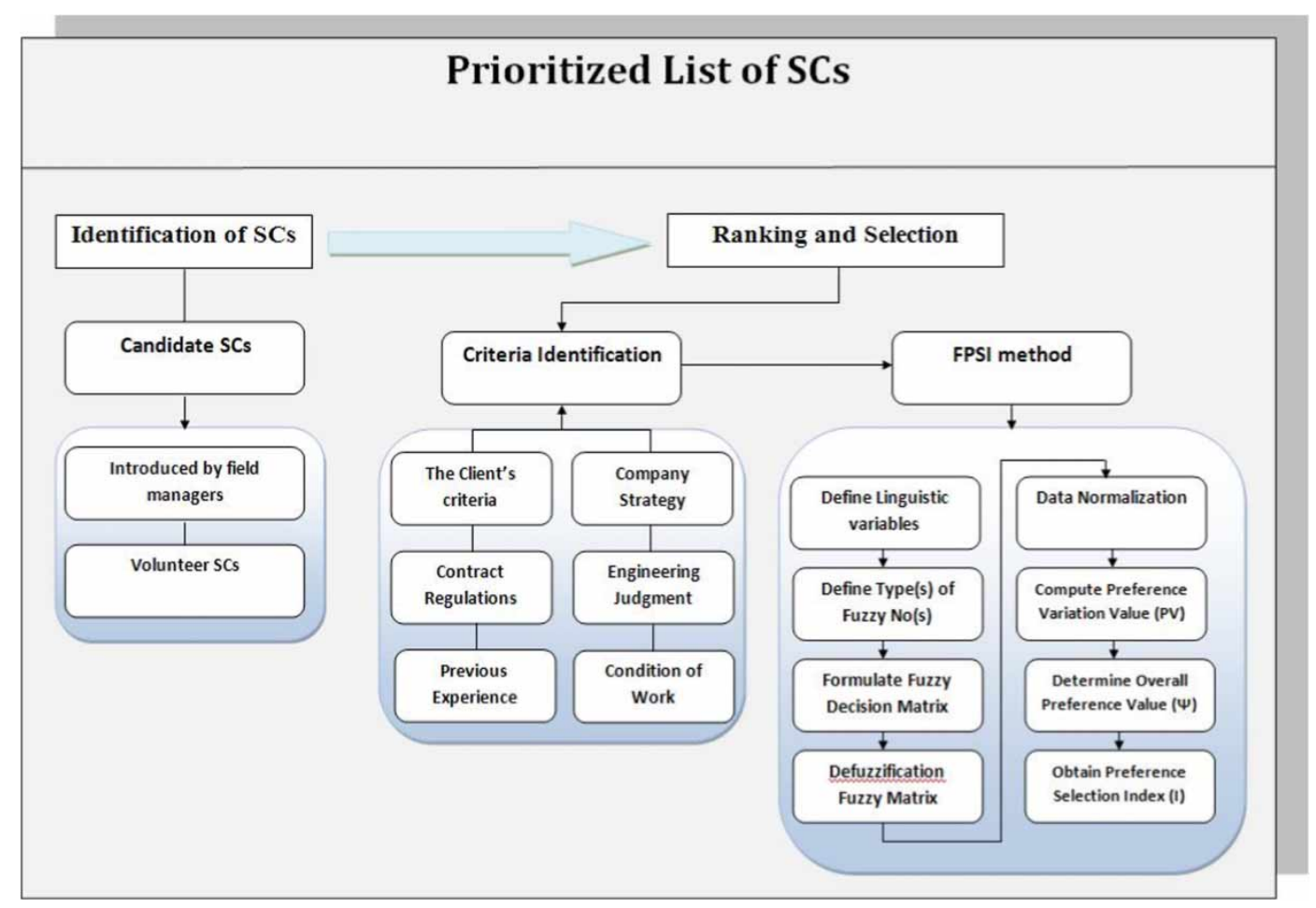

Fig. 1. A SC selection method 
for rating alternatives, experts can state their opinions in linguistic terms for using in the fuzzy set theory. Finally, this model presents a ranked list of SCs, which facilitate GC's decision-making. Generally, the fuzzy decision making framework consists of the following steps:

1. Defining and specifying the types of fuzzy numbers and their membership functions to be used by decision makers;

2. Establishing the scale of preference structure to be used by decision makers;

3. Assigning the fuzzy values to attributes based on their performance on the decision criteria;

4. Aggregating fuzzy numbers among the decision makers;

5. Defuzzification;

6. Determination of global importance or overall value of each of the decision criterion;

7. Ranking of alternatives.

Detailed steps of the model are given in the following methodology.

\subsection{Model steps}

a) Identification of SCs. Identification of SCs who are capable of doing some special tasks is necessary. Identification of SCs can be done by two approaches. In the first approach some SCs can be introduced by field managers. Field managers are the best people who observe the performance of SCs and according to their observations they prefer to work with SCs who have positive cooperation in previous work. Another style of SC identification is a bidding process. Especially considering specific work, GCs need to prepare an announcement for identifying volunteer SCs. Choosing one of those approaches completely depends on the company strategy and types of work;

b) Criteria Identification. The authors believe that criteria identification is a dynamic and variable process, which changes from situation to situation or project to project due to the complexity and uniqueness of construction projects. In special conditions, GCs may eliminate or reduce their attention to some criteria. The existence of a framework for defining a set of criteria is a useful tool, which prevents disregard for principal criteria. This paper puts forth two contributions. Firstly, according to Hartmann et al. (2009), SC's criteria for evaluation should cover four main categories including cost, quality, cooperation, and technical know-how. Satisfying the client criteria, contract regulation, company strategy, and engineering judgment can also be taken into consideration. Regarding these two suggestions, GCs can define a set of criteria for various situations and localize them based on their needs;

c) FPSI Method. For the first time, Maniya and Bhatt (2010) presented the PSI method and used it in the selection of material. The PSI method is a systematic scientific method or tool, which calculates the relative preference of criteria without assigning relative importance among criteria. The innovation of this paper is a combination of linguistic variables in determining the preference of alternatives regarding each attribute and the concept of PSI method. The nature of criteria for selection of SCs is diverse so the evaluation unit of criteria is categorized into two groups. Some of them can be expressed as a crisp number and others can be stated based on linguistic terms. Because linguistic terms are used in the vague and unclear environment, for working with linguistic terms, the authors develop fuzzy PSI (FPSI) method. A combination of the PSI method and fuzzy set theory in this paper is the main contribution of the authors. The details of FPSI are presented in the steps below:

1. Step I: Identifying the goal. Find out the SC alternatives, selection criteria and measures for the given application. This phase was done in sections " $a$ " and " $b$ ";

2. Step II: Defining linguistic terms and fuzzy numbers. A linguistic variable is a variable, which is expressed in linguistic terms. The concept of a linguistic variable is very useful to describe the situation that is too complex or has lack of information. Zadeh (1965) cited that these linguistic variables can be expressed in fuzzy number form. A fuzzy number is a fuzzy subset of the universe of discourse $X$ that is both convex and normal. There are several fuzzy numbers, but in the construction industry, triangular and trapezoidal fuzzy numbers are the most frequently used (An et al. 2005). In this paper, triangular fuzzy numbers are used to illustrate out approaches, though our approach fit with all types of membership functions. The triangular fuzzy numbers can be denoted as $\tilde{A}=\left(a_{1}, a_{2}, a_{3}\right)$, where: $a_{2}$ is the central value $\left(\mu_{\tilde{a}}(x)=1\right) ; a_{1}$ is the left spread; $a_{3}$ is the right spread. Linguistic terms, fuzzy numbers and schema of triangular fuzzy numbers have been presented in Table 1.

In most companies, the selection process is done based on group decision making. When there are $k$ decision makers and each decision maker expresses

Table 1. Linguistic terms and fuzzy numbers

\begin{tabular}{lcc}
\hline $\begin{array}{l}\text { Linguistic } \\
\text { term }\end{array}$ & $\begin{array}{c}\text { Triangular Fuzzy } \\
\text { Number }\end{array}$ & $\begin{array}{c}\text { Triangular Fuzzy } \\
\text { Number }\end{array}$ \\
\hline $\begin{array}{l}\text { Very Good } \\
(\text { VG) }\end{array}$ & $(7.5,10,10)$ & \\
Good (G) & $(5,7.5,10)$ \\
Medium (M) & $(2.5,5,7.5)$ \\
Poor (P) & $(0,2.5,5)$ & \\
Very Poor & $(0,0,2.5)$ & \\
$\quad$ (PL) & &
\end{tabular}


his/her opinion as $A_{l}=\left(a_{j l}, a_{j l}, a_{j l}\right)$, the final fuzzy number can be obtained as $A=\left(a_{j 1}, a_{j 2}, a_{j 3}\right)$, where:

$$
\begin{aligned}
& a_{j 1}=\frac{1}{k} \sum_{l=1}^{k} a_{j l 1} \quad l=1,2, \ldots, k ; \\
& a_{j 2}=\frac{1}{k} \sum_{l=1}^{k} a_{j l 2} \quad l=1,2, \ldots, k ; \\
& a_{j 3}=\frac{1}{k} \sum_{l=1}^{k} a_{j l 3} \quad l=1,2, \ldots, k .
\end{aligned}
$$

For a situation in which expert judgments are expressed as crisp numbers, their opinion's overall average can be considered;

3. Step III: Defuzzification. Working with crisp numbers is absolutely simple, however it is not easy when fuzzy numbers are concerned. Thus, it would be a problem to rank the overall score of each alternative in the fuzzy model. One of the most applicable fuzzy ranking methods is the centroid index method. According to this method, the geometric center of each fuzzy number would be calculated to compare fuzzy numbers (Chen et al. 1992). Each geometric center corresponds to an $x$ value on the horizontal axis and a $y$ on the vertical axis. There are different ideas for using this method. Yager (Yager, Filev 1994) used only an $x$ value for comparing fuzzy numbers. In this paper, the centroid index is used with Yager's approach. The deffuzified index centroid (DIC) of $x$ value can be expressed as:

$$
D I C=\frac{\sum_{x_{\min }}^{x_{\max }} x A(x)}{\sum_{x_{\min }}^{x_{\max }} A(x)} ;
$$

4. Step IV: Formulating the decision matrix. When $A=\left\{A_{i}, i=1,2,3, \ldots, N\right\}$ is a set of alternatives and $C=\left\{C_{j}, j=1,2,3, \ldots, M\right\}$ is a set of decision criteria, $x_{i j}$ is the performance of alternative $A_{i}$ when it is evaluated based on criterion $C_{j}$. It is necessary to express that for linguistic variables $x_{i j}$ is the defuzzified value obtained from $\mathrm{Eq}$ (2). As a result, the decision matrix can be formulated as the matrix below:

\begin{tabular}{lllll}
\hline & \multicolumn{5}{c}{$C_{j}$} \\
\cline { 2 - 5 }$A_{i}$ & $C_{1}$ & $C_{2}$ & $\ldots$ & $C_{m}$ \\
\hline$A_{1}$ & $x_{11}$ & $x_{12}$ & $\ldots$ & $x_{1 n}$ \\
$A_{2}$ & $x_{21}$ & $x_{22}$ & $\ldots$ & $x_{2 n}$ \\
$\ldots$ & $\ldots$ & $\ldots$ & $\ldots$ & $\ldots$ \\
$A_{n}$ & $x_{m 1}$ & $x_{m 2}$ & $\ldots$ & $x_{m n}$ \\
\hline
\end{tabular}

5. Step V: The data normalization: Criteria used in the evaluation phase of SCs have various measurement units for which a comparison is not realistic. Transferring performance rating with different measurement units in a decision matrix into a compatible unit normalization process is necessary. If the expectancy is the larger-the-better (i.e. profit), then the original attribute performance can be normalized as follows:

$$
R_{i j}=\frac{x_{i j}}{x_{j}^{\max }}
$$

If the expectancy is the smaller-the-better (i.e. cost), then the original attribute performance can be normalized as follows:

$$
R_{i j}=\frac{x_{j}^{\min }}{x_{i j}}
$$

where $x_{i j}$ is the attribute measure $(i=1,2,3, \ldots, N)$ and $(j=1,2,3, \ldots, M)$ (Maniya, Bhat 2010);

6. Step VI: Computing preference variation value $\left(P V_{j}\right)$. Calculation of preference variation value $\left(P V_{j}\right)$ for each attribute is the main concern of this step. In order to obtain this purpose, a sample variance analogy is used as follows:

$$
P V_{j}=\sum_{i=1}^{N}\left[R_{i j}-\bar{R}_{j}\right]^{2}
$$

where $\bar{R}_{j}$ is the mean of normalized value of attribute $j$ and $\bar{R}_{j}=\frac{1}{N} \sum_{i=1}^{N} R_{i j}$;

7. Step VII: Determining the overall preference value $\left(\Psi_{j}\right)$. For calculation of overall preference value $\left(\Psi_{j}\right)$ finding deviation $\left(\Phi_{j}\right)$ in preference value $\left(P V_{j}\right)$ is necessary. This variable can be obtained as Eq. (6):

$$
\Phi_{j}=1-P V_{j},
$$

and overall preference value $\left(\Psi_{j}\right)$ is determined using the following equation:

$$
\Psi_{j}=\frac{\Phi_{j}}{\sum_{j=1}^{M} \Phi_{j}} .
$$

The overall preference value of all criteria should be one, i.e. $\sum_{j} \Psi_{j}=1$;

8. Step VIII: Obtaining the preference selection index $\left(I_{j}\right)$. The preference selection index is a tool for ranking alternatives and by using $I_{j}$ the rank of each SC will be cleared. The preference selection index can be calculated as the following equation:

$$
I_{i}=\sum_{j=1}^{M}\left(R_{i j} \times \Psi_{j}\right) .
$$


Table 2. Bridge specifications

\begin{tabular}{ll}
\hline Span & $40 \mathrm{~m}$ \\
Height & $10 \mathrm{~m}$ \\
Reinforcement Concrete & $847 \mathrm{~m}^{3}$ \\
Duration & 6 months \\
Estimated Cost & 850000 million dollars \\
\hline
\end{tabular}

\section{Case study}

A real case study is presented to illustrate the application of the proposed SC methods and to demonstrate the model implication in a real situation. In the present case a major international contractor has been involved in an EPC project. The project is a $50 \mathrm{~km}$ length highway. Main contractor intends to subcontract the construction of two bridges to a qualified subcontractor. Table 2 demonstrates the specifications of each bridge.

Regarding the previous experience of company, three SCs were selected for more evaluations. Evaluation and selection of SCs will be done with respect to criteria derived from investigation conducted by Arslan et al. (2008) (Fig. 2).

After defining criteria and $\mathrm{SC}$ candidates with respect to the introduced linguistic terms (Step II), the decision matrix should be constituted in the following step. Project manager, site manager, project technical director and project execution director constituted a team for group decision making. Tables 3 and 4 represent their judgments and the normalized decision matrix, respectively.

According to the normalized decision matrix and following steps 6 and 7, the overall preference of attributes is calculated as shown in Fig. 3.

Finally, the overall preference selection index $\left(I_{i}\right)$ is calculated as shown in Table 5 and implementing step 8.

\section{Discussion and consistency test}

In view of the fact that the model presents a new approach in SC selection, the test of the proposed model is necessary with previous scientific work. For determining the rate of consistency of this model with others, a fuzzy decision framework for contractor selection suggested by Sing and Tiong (2005) is selected. They developed a model based on Shapley values for evaluating the importance of criteria and fuzzy set theory in assessing alternatives. They illustrate a hypothetical example for implementation of their models. There are four contractors (A, B, C, and D) and three criteria entitled $\mathrm{C} 1, \mathrm{C} 2$ and $\mathrm{C} 3$. Their model calculates the weight of each criterion

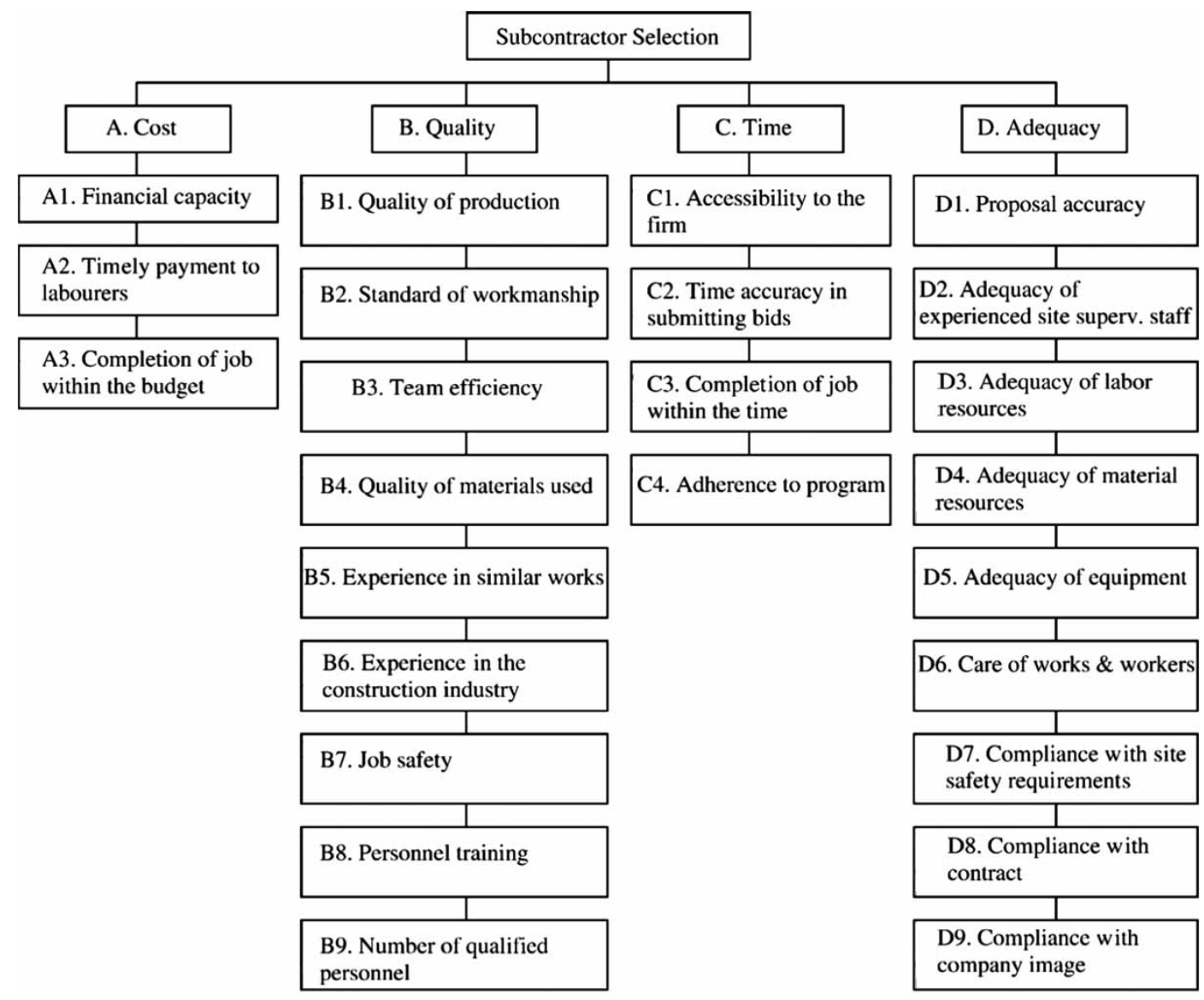

Fig. 2. Evaluation criteria for sub-contractor selection (Arslan et al. 2008) 


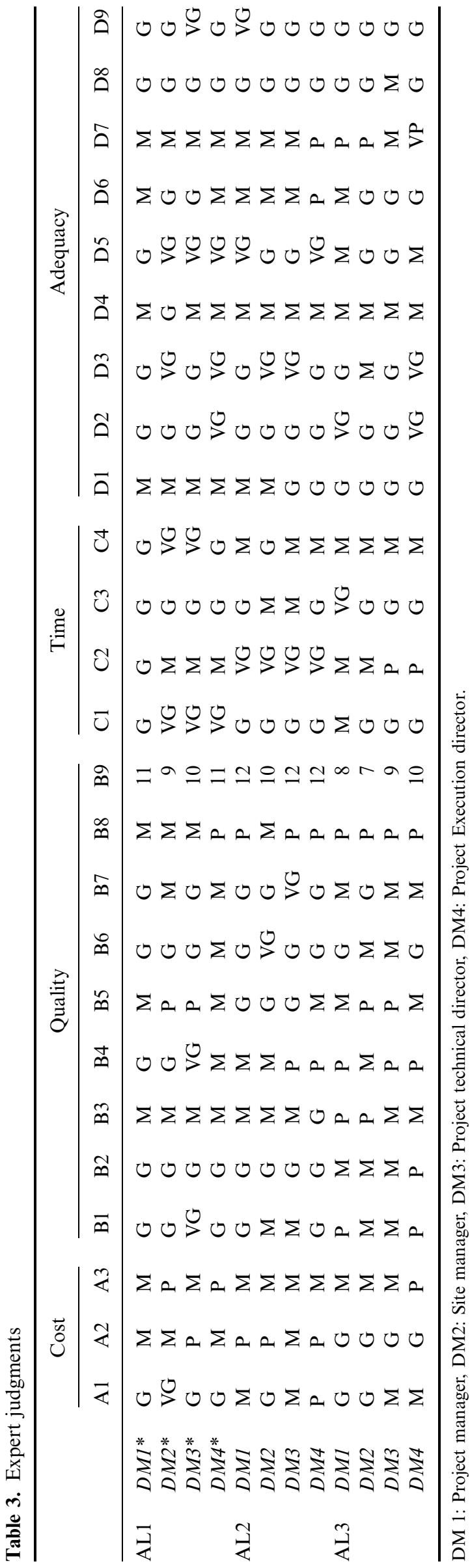

based on the Shapley approach so the relative importance of criteria $\mathrm{C} 1, \mathrm{C} 2$ and $\mathrm{C} 3$ are $0.325,0.3$, and 0.375 , respectively. The decision matrix is:

$$
\left(\begin{array}{cccc}
A & B & C & D \\
0.921 & 0.860 & 0.845 & 1.004 \\
0.725 & 0.836 & 0.706 & 0.656 \\
0.810 & 0.798 & 0.688 & 0.564
\end{array}\right) .
$$

Results of implementing steps 5 to 8 of the FPSI method are as follows.

Normalized decision matrix is:

$$
\left(\begin{array}{cccc}
A & B & C & D \\
0.917 & 0.857 & 0.842 & 1.0 \\
0.867 & 1.0 & 0.844 & 0.785 \\
1.0 & 0.985 & 0.849 & 0.696
\end{array}\right) .
$$

The overall preference value is calculated in Table 6. Table 7.

The preference selection index $\left(I_{j}\right)$ is provided in

For more confidence, the authors present a new problem solved by Shemshadi et al. (2011). They evaluated and ranked suppliers with the use of VIKOR approach. Authors solve the numerical example developed in their paper. According to their example, there are four suppliers and five criteria. Decision makers evaluated alternatives with respect to the five criteria based fuzzy linguistic terms. After rating alternatives, the deffuzified decision matrix was developed. This paper uses the deffuzified decision matrix and FPSI method for ranking alternatives. Steps 5 to 8 are used as follows.

The decision matrix:

$$
\left(\begin{array}{cccccc} 
& C_{1} & C_{2} & C_{3} & C_{4} & C_{5} \\
A_{1} & 0.7 & 0.7 & 0.72 & 0.72 & 0.79 \\
A_{2} & 0.65 & 0.7 & 0.72 & 0.72 & 0.7 \\
A_{3} & 0.85 & 0.7 & 0.58 & 0.65 & 0.87 \\
A_{4} & 0.85 & 0.7 & 0.7 & 0.7 & 0.72
\end{array}\right) .
$$

Normalized decision matrix:

$$
\left(\begin{array}{cccccc} 
& C_{1} & C_{2} & C_{3} & C_{4} & C_{5} \\
A_{1} & 0.82 & 1.0 & 0.83 & 1.0 & 0.91 \\
A_{2} & 0.76 & 1.0 & 0.83 & 1.0 & 0.81 \\
A_{3} & 1.0 & 1.0 & 0.67 & 0.90 & 1.0 \\
A_{4} & 1.0 & 1.0 & 1.0 & 0.92 & 0.83
\end{array}\right) .
$$

Table 8.

The overall preference value $\left(\Psi_{j}\right)$ is presented in Table 9.

The accuracy of proposed model was examined by comparison of the results of model to two previous scientific works. The comparison results show that the results of the FPSI method in the selection of contractors are similar to other scientific work especially in determining the best and worst alternatives. 


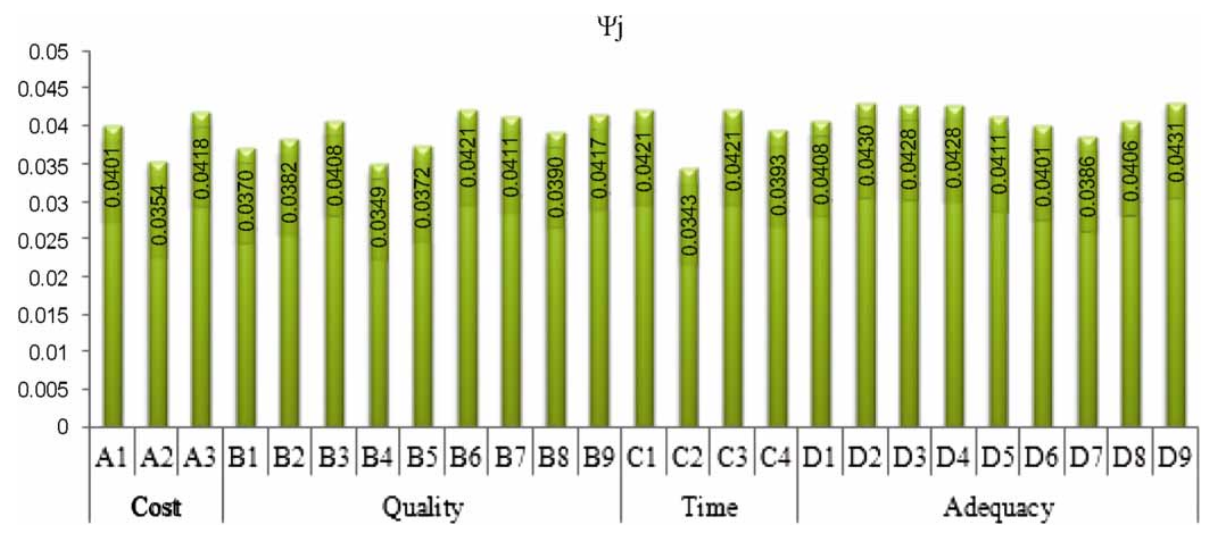

Fig. 3. Scheme of overall preference of attributes

Table 4. Normalized decision matrix

\begin{tabular}{|c|c|c|c|c|c|c|c|c|c|c|c|c|c|}
\hline & \multicolumn{3}{|c|}{ Cost } & & \multicolumn{9}{|c|}{ Quality } \\
\hline & $\mathrm{Al}$ & A2 & A3 & & & B2 & B3 & B4 & B5 & B6 & B7 & B8 & B9 \\
\hline AL1 & 1.000 & 0.584 & 0.750 & & & 1.000 & 0.899 & 1.000 & 0.545 & 0.861 & 0.782 & 1.000 & 0.891 \\
\hline AL2 & 0.626 & 0.417 & 1.000 & & & 1.000 & 1.000 & 0.510 & 1.000 & 1.000 & 1.000 & 0.715 & 1.000 \\
\hline \multirow[t]{3}{*}{ AL3 } & 0.782 & 1.000 & 0.876 & & & 0.584 & 0.674 & 0.425 & 0.545 & 0.782 & 0.705 & 0.571 & 0.739 \\
\hline & \multicolumn{4}{|c|}{ Time } & \multicolumn{9}{|c|}{ Adequacy } \\
\hline & $\mathrm{C} 1$ & $\mathrm{C} 2$ & $\mathrm{C} 3$ & $\mathrm{C} 4$ & $\mathrm{Dl}$ & D2 & D3 & D4 & D5 & D6 & D7 & D8 & D9 \\
\hline AL1 & 1.000 & 0.563 & 0.939 & 1.000 & 0.667 & 0.968 & 1.000 & 1.000 & 1.000 & 0.908 & 1.000 & 1.000 & 1.000 \\
\hline AL2 & 0.850 & 1.000 & 0.782 & 0.679 & 0.833 & 0.909 & 1.000 & 0.888 & 0.940 & 0.637 & 0.876 & 0.667 & 1.000 \\
\hline AL3 & 0.780 & 0.375 & 1.000 & 0.603 & 1.000 & 1.000 & 0.888 & 0.888 & 0.709 & 1.000 & 0.556 & 0.917 & 0.939 \\
\hline
\end{tabular}

Table 5. The overall preference selection index and project ranking

\begin{tabular}{lcc}
\hline & SCORE & RANK \\
\hline AL1 & 0.8982 & 1 \\
AL2 & 0.8491 & 2 \\
AL3 & 0.7603 & 3 \\
\hline
\end{tabular}

Table 6. The overall preference value

\begin{tabular}{cccc}
\hline & \multicolumn{3}{c}{ Criteria } \\
\cline { 2 - 4 } & $\mathrm{C} 1$ & $\mathrm{C} 2$ & $\mathrm{C} 3$ \\
\hline$\Psi_{j}$ & 0.3367 & 0.3331 & 0.3302 \\
\hline
\end{tabular}

Table 7. FPSI method and fuzzy decision frame work comparison results

\begin{tabular}{lccccc}
\hline & \multicolumn{2}{c}{$\begin{array}{c}\text { Results of FPSI } \\
\text { method }\end{array}$} & & \multicolumn{2}{c}{$\begin{array}{c}\text { Results of fuzzy } \\
\text { decision framework }\end{array}$} \\
\cline { 2 - 3 } \cline { 5 - 6 } Contractor & $\left(I_{j}\right)$ & Rank & & Overall score & Rank \\
\hline A & 0.9279 & 2 & & 0.8206 & 2 \\
B & 0.9468 & 1 & & 0.8296 & 1 \\
C & 0.8451 & 3 & & 0.7444 & 3 \\
D & 0.8279 & 4 & & 0.7346 & 4 \\
\hline
\end{tabular}

Table 8. The overall preference value

\begin{tabular}{cccccc}
\hline & \multicolumn{5}{c}{ Criteria } \\
\cline { 2 - 6 } & $\mathrm{C} 1$ & $\mathrm{C} 2$ & $\mathrm{C} 3$ & $\mathrm{C} 4$ & $\mathrm{C} 5$ \\
\hline$\left(\Psi_{j}\right)$ & 0.197 & 0.204 & 0.198 & 0.202 & 0.199 \\
\hline
\end{tabular}

Table 9. FPSI method and VIKOR comparison results

\begin{tabular}{lccccc}
\hline & $\begin{array}{c}\text { Results of FPSI } \\
\text { method }\end{array}$ & & \multicolumn{2}{c}{$\begin{array}{c}\text { Results of VIKOR } \\
\text { approach }\end{array}$} \\
\cline { 2 - 3 } \cline { 5 - 6 } Contractor & $\left(I_{j}\right)$ & Rank & & Overall score & Rank \\
\hline A & 0.9128 & 3 & & 0.57 & 3 \\
B & 0.8806 & 4 & & 0.74 & 4 \\
C & 0.9143 & 2 & & 0.5 & 2 \\
D & 0.9600 & 1 & & 0.17 & 1 \\
\hline & \multicolumn{4}{c}{ Actually, the proposed method is simple and applic- } \\
able in different situations. With respect to the \\
calculations conducted by other approaches, FPSI \\
method is very simple and decision makers can obtain \\
the best and worst answer with minimum calculation. \\
This method eliminates the weighting process so it can \\
save time and money in the SC evaluation and selection.
\end{tabular}


Table 10. Results of questionnaire responses

\begin{tabular}{lcrr}
\hline Criteria & $\begin{array}{r}\text { Positive } \\
\text { Answer }\end{array}$ & $\begin{array}{r}\text { Neutral } \\
\text { Answer }\end{array}$ & $\begin{array}{r}\text { Negative } \\
\text { Answer }\end{array}$ \\
\hline Comprehensiveness & $63 \%$ & $2.5 \%$ & $34.5 \%$ \\
Applicability & $71 \%$ & $1.3 \%$ & $27.7 \%$ \\
$\begin{array}{l}\text { User-friendliness } \\
\text { Practitioner's }\end{array}$ & $58 \%$ & $4 \%$ & $38 \%$ \\
$\quad$ support & $54 \%$ & $12 \%$ & $34 \%$ \\
\hline
\end{tabular}

For investigating the applicability, comprehensiveness, and user-friendliness of model, Ravanshadnia et al. (2010a) developed a structured questionnaire. In this paper, the authors developed a structured questionnaire for evaluating the proposed model. This questionnaire consists of four main questions as below:

1. Comprehensiveness: Does the FPSI method cover the required $\mathrm{SC}$ selection considerations?

2. Applicability: Is the FPSI method applicable for SC selection in construction companies?

3. User-friendliness: Is it easy to use the FPSI method?

4. Practitioner's support: Do you support the implementation of proposed framework by this paper in your company for SC selection?

The test was implemented in Iranian large-size (Grade 1) construction companies. The government qualified 182 contractors as Grade 1 in 2011. Assuming a $95 \%$ confidence interval, the test should cover at least 45 companies. Authors distributed questionnaire to companies and finally total 52 companies answered to questionnaire. Table 10 shows the results of analyzing responses.

Results revealed in the above table assured authors about the comprehensiveness, applicability, user-friendliness and costumer's support of proposed framework by this paper.

\section{Conclusions}

This paper presents a comprehensive description of a proposed SC selection framework based on the FPSI method. In some circumstances, decision makers are eager to eliminate the weighting criteria phase for some reasons such as conflict opinions, lack of time, inadequate information, lack of historical data. The proposed method eliminated the weighting criteria phase and the relative importance of each attribute is calculated based on decision maker's opinions on evaluation of alternatives by the FPSI method. Due to lack of precise information and complexity of each project, which are the permanent problems of the construction industry, linguistic terms are used for expressing expert's opinions. Comparing the results of the proposed method with previous attempts is considered as a consistency test. Authors strongly believe that if done with careful attention to all limitations and objects of models, such a comparison can provide opportunity for researchers to distinguish their own strengths and weaknesses. Results of comparisons confirm the model accuracies. In most previous research, proposing a complicated model, which necessitates very high calculation, is clear but in this method users can obtain their own desired answer in a short period of time.

Owning to the fact that the authors are familiar with all aspects of the subject, future work can be defined in some areas such as SC portfolio selection, surveying on interaction and interdependency of SCs in a project, and minimizing or optimizing the interaction of SC portfolio.

\section{References}

Ahmad, I.; Minkarah, I. 1988. Questionnaire survey on bidding in construction, Journal of Management in Engineering ASCE 4(3): 229-243. http://dx.doi.org/10. 1061/(ASCE)9742-597X(1988)4:3(229)

An, M.; Baker, C.; Zeng, J. 2005. A fuzzy-logic-based approach to qualitative risk modeling in the construction process, World Journal of Engineering 2(1): $1-12$.

Arslan, G.; Kivrak, S.; Birgonul, M. T.; Dikmen, I. 2008. Improving sub-contractor selection process in construction projects: web-based sub-contractor evaluation system (WEBSES), Automation in Construction 17(4): 480-488.

http://dx.doi.org/10.1016/j.autcon.2007.08.004

Chen, S.-J.; Hwang, C.-L.; Hwang, F. P. 1992. Fuzzy multiple attribute decision-making: methods and applications. Berlin: Springer-Verlag. 536 p. http://dx.doi.org/10.1007/978-3-642-46768-4

Chu, T.-C. 2002. Selecting plant location via a fuzzy TOPSIS approach, The International Journal of Advanced Manufacturing Technology 20: 859-864. http://dx.doi.org/10.1007/s001700200227

Diekmann, J. E. 1981. Cost-plus contractor selection: a case study, Journal of the Technical Councils of ASCE 107(1): 13-25.

Edwards, K. L.; Deng, Y.-M. 2007. Supporting design decision-making when applying materials in combination, Materials \& Design 28(4): 1288-1297. http://dx.doi.org/10.1016/j.matdes.2005.12.009

Elazouni, A. M.; Metwally, F. G. 2000. D-SUB: decision support system for subcontracting construction works, Journal of Construction Engineering and Management ASCE 126(3): 191-200. http://dx.doi.org/10.1061/ (ASCE)0733-9364(2000)126:3(191)

Fodor, J.; Roubens, M. 1994. Fuzzy preference modeling and multi criteria decision support. Kluwer, Dordrecht. $276 \mathrm{p}$.

Fong, P. S.-W.; Choi, S. K.-Y. 2000. Final contractor selection using analytical hierarchy process, Construction Management and Economics 18(5): 547-557. http://dx.doi.org/10.1080/014461900407356

Gheorghe, R. 2005. A new fuzzy multi criteria decision aid method for conceptual design. $\mathrm{PhD}$ thesis. $\mathrm{EPF}$ Lausanne, Institute of Production and Robotics Ecole Polytechnique Federale de Lausanne, Switzerland. 
Ghoudsypour, S. H.; O'Brien, C. O. 1998. A decision support system for supplier selection using an integrated analytic hierarchy process and linear programming, International Journal of Production Economics 56-57: 199-212. http://dx.doi.org/10.1016/S0925-5273(97)00009-1

Hartmann, A.; Ling, F. Y. Y.; Tan J. S. H. 2009. Relative importance of subcontractor selection criteria: evidence from Singapore, Journal of Construction Engineering and Management ASCE 135(9): 826-832. http://dx.doi.org/10.1061/(ASCE)0733-9364(2009) 135:9(826)

Hatush, Z.; Skitmore, M. 1998. Contractor selection using multi criteria utility theory: an additive model, Building and Environment 33(2-3): 105-115. http://dx.doi.org/10.1016/S0360-1323(97)00016-4

Jee, D.-H.; Kang, K.-J. 2000. A method for optimal material selection aided with decision making theory, Materials \& Design 21(3): 199-206. http://dx.doi.org/10.1016/S0261-3069(99)00066-7

Kahraman, C.; Çevik, S.; Ates, N. Y.; Gülbay, M. 2007. Fuzzy multi-criteria evaluation of industrial robotic system, Computers \& Industrial Engineering 52(4): 414-433. http://dx.doi.org/10.1016/j.cie.2007.01.005

Mahdi, I. M.; Riley, M. J.; Fereig, S. M.; Alex, A. P. 2002. A multi-criteria approach to contractor selection, Engineering Construction and Architectural Management 9(1): 29-37.

Maniya, K.; Bhatt, M. G. 2010. A selection of material using a novel type decision-making method: preference selection index method, Materials \& Design 31(4): 1785-1789.

http://dx.doi.org/10.1016/j.matdes.2009.11.020

Mbachu, J. 2008. Conceptual framework for the assessment of subcontractors' eligibility and performance in the construction industry, Construction Management and Economics 26(5): 471-484. http://dx.doi.org/10.1080/01446190801918730

Mikhailov, L. 2004. Group prioritization in the AHP by fuzzy preference programming method, Computers \& Operations Research 31(2): 293-301. http://dx.doi.org/10.1016/S0305-0548(03)00012-1

Oo, B.-L.; Drew, D. S.; Lo, H.-P. 2008. A comparison of contractors' decision to bid behaviour according to different market environments, International Journal of Project Management 26(4): 439-447. http://dx.doi.org/10.1016/j.ijproman.2007.06.001

Ravanshadnia, M.; Rajaie, H.; Abbasian, H. R. 2010a. Hybrid fuzzy MADM project-selection model for diversified construction companies, Canadian Journal of Civil Engineering 37(8): 1082-1093. http://dx.doi.org/10.1139/L10-048

Ravanshadnia, M.; Abbasian, H. R.; Rajaie, H. 2010b. Selecting engineering partner for EPC projects; a fuzzy AHP approach, International Journal of Management Science and Engineering Management 5(4): 277-283.

Ravanshadnia, M.; Rajaie, H.; Abbasian, H. R. 2011. A comprehensive $\mathrm{Bid} / \mathrm{No}-\mathrm{Bid}$ decision making framework for construction companies, Iranian Journal of
Science and Technology Transaction B-Engineering 35(C1): 95-103.

Shemshadi, A.; Shirazi, H.; Toreihi, M.; Tarokh, M. J. 2011. A fuzzy VIKOR method for supplier selection based on entropy measure for objective weighting, Expert Systems with Applications 38(10): 12160-12167. http://dx.doi.org/10.1016/j.eswa.2011.03.027

Shash, A. A.; Abdul-Hadi, N. H. 1993. The effect of contractor size on mark-up size decision in Saudi Arabia, Construction Management and Economics 11(6): 421-429. http://dx.doi.org/10.1080/01446199300000048

Shash, A. 1993. Factors considered in tendering decisions by top UK contractors, Construction Management and Economics 11(2): 111-118. http://dx.doi.org/10.1080/01446199300000004

Shash, A. A. 1998. Bidding practices of subcontractors in Colorado, Journal of Construction Engineering and Management ASCE 124(3): 219-225. http://dx.doi. org/10.1061/(ASCE)0733-9364(1998)124:3(219)

Shimizu, J. Y.; Cardoso, F. F. 2002. Subcontracting and cooperation network in building construction: a literature review, in The $10^{\text {th }}$ Conference of the international Group for Lean Construction IGLC-10, 6-8 August, 2002, Gramado, Brazil, 1-13.

Sing, D.; Tiong, R. L. K. 2005. A fuzzy decision framework for contractor selection, Journal of Construction Engineering and Management ASCE 131(1): 62-70. http://dx.doi.org/10.1061/(ASCE)0733-9364(2005)131: $1(62)$

Tserng, H. P.; Lin, P. H. 2002. An accelerated subcontracting and procuring model for construction projects, Automation in Construction 11(1): 105-125. http://dx.doi.org/10.1016/S0926-5805(01)00056-5

Wang, Y.-M.; Elhag, T. M. S. 2006. Fuzzy TOPSIS method based on alpha level sets with an application to bridge risk assessment, Expert Systems with Applications 31(2): 309-319.

http://dx.doi.org/10.1016/j.eswa.2005.09.040

Wang, J.; Xu, Y.; Li, Z. 2009a. Research on project selection system of pre-evaluation of engineering design project bidding, International Journal of Project Management 27(6): 584-599.

http://dx.doi.org/10.1016/j.ijproman.2008.10.003

Wang, J.-W.; Cheng, C.-H.; Huang, K.-C. 2009b. Fuzzy hierarchical TOPSIS for supplier selection, Applied Soft Computing 9(1): 377-386. http://dx.doi.org/10.1016/j.asoc.2008.04.014

Xiaolin, Y. U.; Heng, S.; Big, Y. 2008. A supplier selection method for general contractor based on benchmark thinking and case-based reasoning, in the 4th International Conference on Wireless Communications, Networking and Mobile Computing (WiCOM'08), 12-14 October, 2008, 1-4.

Yager, R. R.; Filev, D. P. 1994. Essentials of Fuzzy Modeling and Control. New York: John Wiley \& Sons. 408 p.

Yin, H.; Wang, Z.; Yu, J.; Ji, Z.; Ni, H. 2009. Application of DEA Cross-evaluation model in project dynamic alliance subcontractors selection, in International Workshop on Intelligent Systems and Applications (ISA 2009), 23-24 May, 2009, 1-4. http://dx.doi.org/10.1109/IWISA.2009.5072743 
Zadeh, L. A. 1965. Fuzzy sets, Information and Control 8(3): 338-353. http://dx.doi.org/10.1016/S0019-9958(65)90241-X

Zavadskas, E. K.; Vilutiene, T.; Turskis, Z.; Tamosaitiene, J. 2010. Contractor selection for construction works by applying SAW-G and TOPSIS grey techniques, Journal of Business Economics and Management 11(1): 34-55.

http://dx.doi.org/10.3846/jbem.2010.03
Zeng, J.; An, M.; Smith, N. J. 2007. Application of a fuzzy based decision-making methodology to construction project risk assessment, International Journal of Project Management 25(6): 589-600. http://dx.doi.org/10.1016/j.ijproman.2007.02.006

Zhang, W. 2004. Handover decision using fuzzy MADM in heterogeneous networks, in 2004 IEEE Wireless Communications and Networking Conference, 21-25 March, 2004. Vol. 2, 653-658.

Hamidreza ABBASIANJAHROMI. PhD Candidate in Construction Engineering and Management at Amirkabir University of Technology, Tehran, Iran. He is member of Iran Project Management Association. His research interests include decision-making problems in construction, application of fuzzy set theory in construction, project selection, risk management and contractor/subcontractor selection and assessment.

Hossein RAJAIE. Dr, Assistant Professor of Civil Engineering Faculty at Amirkabir University of Technology, Tehran, Iran. He is member of Concrete Research Center of Amirkabir University, academic member of Building and Housing Research Center, Tehran, Iran. His research interests are portfolio management, decision-making problems in construction, project selection, contractor selection, material Selection in construction industry. 